\title{
Changes and patterns in biologically relevant temperatures in Europe 1941-2000
}

\author{
T. H. Sparks ${ }^{1,3, *}$, A. Aasa ${ }^{2}$, K. Huber ${ }^{1}$, R. Wadsworth ${ }^{1}$ \\ ${ }^{1}$ NERC Centre for Ecology and Hydrology, Monks Wood, Abbots Ripton, Huntingdon, Cambridgeshire PE28 2LS, UK \\ ${ }^{2}$ Department of Geography, University of Tartu, 51014 Tartu, Estonia \\ ${ }^{3}$ Present address: 68 Girton Road, Girton, Cambridge CB3 0LN, UK
}

\begin{abstract}
We took daily near-surface air temperature data from across Europe to calculate a series of 12 biologically relevant temperature summaries. Mean values for two $30 \mathrm{yr}$ periods, 1941-1970 and 1971-2000, were compared and rates of change calculated for those meteorological stations with sufficient data. We generated contour maps for these temperature summaries for both $30 \mathrm{yr}$ periods and for the difference between them; we believe these are the first such maps for over a century. Change was most pronounced and most consistent in those variables describing the onset of spring. Between 1971 and 2000, the thermal start of the growing season began on average $0.36 \mathrm{~d} \mathrm{yr}^{-1}$ earlier and ended $0.10 \mathrm{~d} \mathrm{yr}^{-1}$ later, suggesting an $11 \mathrm{~d}$ earlier beginning and $3 \mathrm{~d}$ later end of the growing season over the $30 \mathrm{yr}$ period. For all but one of the temperature summaries, change has accelerated in recent time; however, change was not uniform across Europe.
\end{abstract}

KEY WORDS: Daily temperature - Temperature accumulation · Thresholds · Spring · Autumn . Trends $\cdot$ Warming

Resale or republication not permitted without written consent of the publisher

\section{INTRODUCTION}

In the first of a series of 5 papers, Southern (1938) compared contours of the timing of spring bird migration (isochronal contours) across Europe with contours indicating the date that mean daily air temperatures reached $48^{\circ} \mathrm{F}$ (ca. $9^{\circ} \mathrm{C}$ ) in spring. Southern (1938) confusingly referred to the latter as isotherms but they may be more accurately termed temperature isochrones. These papers are notable for 2 reasons. (1) They indicate extensive phenological networking in a pre-computer era, despite the difficult politics of that decade. More than 160 locations were used, with approximately one-third located in the European zone of the former USSR. It has subsequently not been possible to achieve such extensive collaboration in zoophenology, although more success has been achieved in phytophenology. (2) The use of temperature isochrones as biologically important information was novel. Southern (1938) made use of information published in Bartholomew's Physical Atlas of 1899 (Bartholomew et al. 1899), thus using data that was already well out of date. Meteorological atlases now more typically include information on isotherms, for example winter, summer or annual temperatures. If isochrones are used, they may summarise last spring and first autumn frost dates. We are not aware of European meteorological charts summarising other temperature isochrones (dates on which temperature thresholds are passed) more recent than Bartholomew et al. (1899).

Most international studies on phenology have tended to make use of monthly mean temperatures, because these are more readily available from individual meteorological stations or have been interpolated and gridded for ease of use. However, the European Climate Assessment (Klein Tank et al. 2002) has made available daily near-surface mean air temperatures from individual stations. Consequently, it is possible to derive a number of biologically relevant temperature summaries across Europe. In the present study we take the opportunity to: (1) calculate these summaries for individual stations, (2) examine them for change over time and (3) generate maps showing the contours of these summary variables. 


\section{MATERIALS AND METHODS}

\subsection{Data}

Daily near-surface mean air temperature data for 1941-2000 were extracted from the European Climate Assessment website (http://eca.knmi.nl) (Klein Tank et al. 2002) for all meteorological stations with at least 20 yr of data during the period 1971-2000. Stations ranged in latitude from $29.55^{\circ} \mathrm{N}$ (Elat, Israel) to $76.50^{\circ} \mathrm{N}$ (Hopen, Norway), in longitude from $22.73^{\circ} \mathrm{W}$ (Stykkisholmur, Iceland) to $59.38^{\circ} \mathrm{E}$ (Hoseda Hard, Russia) and in altitude from -23 m (Astrakan, Russia) to $3106 \mathrm{~m}$ (Sonnblick, Austria). Some quality control was performed: e.g. dubious temperatures $>60^{\circ} \mathrm{C}$ and periods of $>10$ consecutive days where the temperature was exactly $0^{\circ} \mathrm{C}$ were omitted. At each meteorological station, years with 5 or more missing values were excluded from further data manipulation.

Overall, 12 summaries of biologically relevant information were calculated for each site and for each year from the daily mean temperature. These were:

(1) number of cold days (mean $<0^{\circ} \mathrm{C}$ ) per year;

(2) number of hot days (mean $>20^{\circ} \mathrm{C}$ ) per year;

(3) first day of the year to cross a $5^{\circ} \mathrm{C}$ threshold;

(4) first day of the year to cross a $10^{\circ} \mathrm{C}$ threshold

(5) first day of the year following the annual maximum temperature to drop below $10^{\circ} \mathrm{C}$;

(6) first day of the year following the annual maximum temperature to drop below $5^{\circ} \mathrm{C}$;

(7) day marking the beginning of the growing season (calculated as the first of 5 consecutive days at or above $5^{\circ} \mathrm{C}$; proposed by Mitchell \& Hulme 2002);

(8) day marking the end of the growing season (calculated as the last of 5 consecutive days at or above $5^{\circ} \mathrm{C}$; proposed by Mitchell \& Hulme 2002);

(9) length of the growing season (the difference between the previous 2; proposed by Mitchell \& Hulme 2002);

(10) annual number of accumulated growing degree days above $0^{\circ} \mathrm{C}$ (GDD0);

(11) annual number of accumulated growing degree days above $5^{\circ} \mathrm{C}$ (GDD5);

(12) day on which the accumulated temperature above $0^{\circ} \mathrm{C}$ reached 200 growing degree days (TSUM200).

The completeness of data was not the same for all variables; for example, some meteorological stations on mountain peaks were so cold that they did not reach the temperature thresholds listed above.

\subsection{Comparison of 1941-1970 and 1971-2000 means}

The mean value for each of the 12 derived variables was calculated for 2 periods (1941-1970 and 1971-2000) for all stations with at least 20 yr of data in both periods. Differences between the period means across Europe for each variable were compared using paired $t$-tests.

\subsection{Trends over time}

For the 256 sites with at least $20 \mathrm{yr}$ of data in the 1971-2000 period, linear regressions of all 12 derived variables against time (year) were carried out and the coefficients (i.e. trends per year) and statistical significance recorded. Linear regressions of the 12 derived variables in the 1941-2000 period against time (year) were carried out for the subset of these sites that additionally had at least $10 \mathrm{yr}$ of data in the 1941-1970 period (234 sites). Once again, coefficients and statistical significance were recorded.

To test whether mean trends across Europe tended to be in one direction, the station coefficients in each of the 2 periods were compared to zero using 1-sample $t$-tests. To test whether trends in the 2 time periods were identical, the station coefficients in the 19412000 and 1971-2000 periods were compared using paired $t$-tests. For each variable, station coefficients in the 1971-2000 period were examined in relation to latitude, longitude and altitude in a multiple regression to see if trends were uniform across Europe or could be explained by one of more of these factors.

\subsection{Maps}

Maps were derived from station means based on at least 20 yr of data in any 30 yr period. For every variable and period a multiple regression model was calculated with the latitude, longitude and altitude of the meteorological station as independent variables. Predicted values for every map pixel (based on latitude, longitude and altitude) were calculated from the multiple regression model. Model residuals were also computed for each station, and were then interpolated for the whole area by an inverse distance weighting (IDW) algorithm to produce a surface. To obtain the final map, the modelled surface was overlaid by the surface of the residuals. All maps were prepared in the ESRI (www.esri.com) ArcMap 9.2 environment.

\section{RESULTS}

\subsection{Comparison of 1941-1970 and 1971-2000 means}

Comparing means for the 2 periods (Table 1) suggests greater differences in spring than in autumn variables. There was an overall reduction in the number of 
Table 1. Derived variables (mean \pm SE) for the periods 1941-2000 and 1971-2000 for European stations with at least 20 yr of data in each period; Diff.: mean difference between the periods calculated. The 2 periods were compared using a paired $t$-test for each variable. Significant results are shown in bold. DOY: day of year; GDD0, GDD5: annual no. of accumulated growing degree days above 0 and $5^{\circ} \mathrm{C}$, respectively; TSUM200: day on which the accumulated temperature above $0^{\circ} \mathrm{C}$ reached 200 growing degree days

\begin{tabular}{|c|c|c|c|c|c|c|}
\hline & $1941-1970$ & $1971-2000$ & Diff. & $t$ & $\mathrm{p}$ & $\mathrm{n}$ \\
\hline 1 Days $<0^{\circ} \mathrm{C}$ & $73.4 \pm 4.3$ & $66.2 \pm 4.3$ & -7.3 & -16.60 & $<0.001$ & 202 \\
\hline 2 Days $>20^{\circ} \mathrm{C}$ & $33.9 \pm 2.8$ & $34.8 \pm 2.7$ & 0.9 & 3.05 & 0.003 & 202 \\
\hline 3 Spring $5^{\circ} \mathrm{C}$ threshold (DOY) & $47.7 \pm 3.1$ & $42.2 \pm 3.1$ & -5.5 & -8.52 & $<0.001$ & 201 \\
\hline 4 Spring $10^{\circ} \mathrm{C}$ threshold (DOY) & $85.1 \pm 3.0$ & $81.2 \pm 3.1$ & -3.9 & -8.31 & $<0.001$ & 196 \\
\hline 5 Autumn $10^{\circ} \mathrm{C}$ threshold (DOY) & $258.9 \pm 2.3$ & $258.2 \pm 2.2$ & -0.7 & -1.76 & 0.081 & 198 \\
\hline 6 Autumn $5^{\circ} \mathrm{C}$ threshold (DOY) & $288.6 \pm 2.0$ & $288.2 \pm 2.0$ & -0.4 & -1.25 & 0.213 & 186 \\
\hline 7 Beginning of growing season (DOY) & $78.4 \pm 3.0$ & $73.6 \pm 3.1$ & -4.8 & -9.42 & $<0.001$ & 198 \\
\hline 8 End of growing season (DOY) & $316.6 \pm 2.1$ & $318.6 \pm 2.2$ & 2.0 & 5.73 & $<0.001$ & 198 \\
\hline 9 Length of growing season (d) & $238.1 \pm 5.0$ & $244.6 \pm 5.2$ & 6.5 & 8.66 & $<0.001$ & 198 \\
\hline 10 GDD0 (degree days) & $3357 \pm 90$ & $3397 \pm 90$ & 40 & 5.97 & $<0.001$ & 200 \\
\hline 11 GDD5 (degree days) & $2017 \pm 71$ & $2027 \pm 71$ & 10 & 1.88 & 0.062 & 202 \\
\hline 12 TSUM200 (DOY) & $93.2 \pm 2.9$ & $88.1 \pm 3.0$ & -5.1 & -9.47 & $<0.001$ & 201 \\
\hline
\end{tabular}

Table 2. Polarity and significance of station regression coefficients of 12 derived variables on year for the periods $1941-2000$ and 1971-2000 (data are number of stations with significant and non-significant trends). Sig.: p < 0.05; ns: p > 0.05. Abbreviations in Table 1

\begin{tabular}{|c|c|c|c|c|c|c|c|c|}
\hline & \multicolumn{4}{|c|}{$1941-2000 \longleftarrow$} & \multicolumn{4}{|c|}{$-1971-2000-$} \\
\hline & \multicolumn{2}{|c|}{ Negative } & \multicolumn{2}{|c|}{ Positive } & \multicolumn{2}{|c|}{ Negative } & \multicolumn{2}{|c|}{ Positive } \\
\hline & Sig. & ns & ns & Sig. & Sig. & ns & ns & Sig. \\
\hline 1 Days $<0^{\circ} \mathrm{C}$ & 92 & 124 & 18 & 0 & 20 & 172 & 59 & 0 \\
\hline 2 Days $>20^{\circ} \mathrm{C}$ & 6 & 73 & 110 & 45 & 2 & 61 & 118 & 70 \\
\hline 3 Spring $5^{\circ} \mathrm{C}$ threshold (DOY) & 46 & 154 & 32 & 2 & 16 & 191 & 43 & 1 \\
\hline 4 Spring $10^{\circ} \mathrm{C}$ threshold (DOY) & 48 & 124 & 55 & 2 & 46 & 154 & 45 & 1 \\
\hline 5 Autumn $10^{\circ} \mathrm{C}$ threshold (DOY) & 6 & 96 & 120 & 9 & 1 & 60 & 169 & 16 \\
\hline 6 Autumn $5^{\circ} \mathrm{C}$ threshold (DOY) & 4 & 85 & 106 & 18 & 1 & 39 & 155 & 30 \\
\hline 7 Beginning of growing season (DOY) & 51 & 127 & 48 & 5 & 32 & 162 & 50 & 5 \\
\hline 8 End of growing season (DOY) & 1 & 85 & 127 & 18 & 2 & 86 & 147 & 14 \\
\hline 9 Length of growing season (d) & 7 & 44 & 118 & 62 & 4 & 48 & 151 & 46 \\
\hline 10 GDD0 (degree days) & 12 & 37 & 96 & 89 & 0 & 5 & 91 & 155 \\
\hline 11 GDD5 (degree days) & 20 & 39 & 105 & 70 & 0 & 10 & 85 & 156 \\
\hline 12 TSUM200 (DOY) & 102 & 107 & 24 & 1 & 31 & 190 & 30 & 0 \\
\hline
\end{tabular}

cold days by an average of ca. $10 \%$ in 1971-2000 compared to 1941-1970; additionally, the spring $5^{\circ} \mathrm{C}$ threshold was reached $5.5 \mathrm{~d}$ earlier, the spring $10^{\circ} \mathrm{C}$ threshold 3.9 d earlier, the thermal start of the growing season $4.8 \mathrm{~d}$ earlier and TSUM200 was attained $5.1 \mathrm{~d}$ earlier in 1971-2000. In contrast, there was only a ca. $3 \%$ increase in the average number of warm days, changes to autumn threshold dates were not significant and the thermal end of the growing season was only $2 \mathrm{~d}$ later. The net consequence was a $6.5 \mathrm{~d}$ average increase in the growing season, a $3 \%$ increase in duration of GDD0 and a non-significant increase in GDD5.

\subsection{Trends in time}

Table 2 summarises the trends and their significance at individual stations. During the 1941-2000 period the mean trend across Europe was towards fewer cold days, more hot days, an earlier thermal spring, a slightly later thermal autumn and hence a longer and warmer growing season. The results essentially repeat what was shown in Table 1 . The consistency of change was most marked for TSUM200, where $89 \%$ of stations had a negative coefficient (towards earlier dates) and $44 \%$ of all stations were significantly earlier.

Table 3 summarises mean station trends (regression coefficients) across Europe. Overall, mean trends across Europe in 1941-2000 were significantly different from zero except for the autumn $10^{\circ} \mathrm{C}$ threshold. Mean trends in the 1971-2000 period were significantly different from zero for all 12 variables. All variables, with the exception of the number of cold days, were significantly more extreme than during the whole 19412000 period (Table 3). The acceleration of change was up to an order of magnitude different; for example, the autumn $10^{\circ} \mathrm{C}$ threshold for the entire period was 
Table 3. European means of the station regression coefficients of the derived variables on year for the periods 1941-2000 and 1971-2000. $t$ : test of the mean value against zero (i.e. no overall change). Significant results are shown in bold. Diff. = Difference between periods (paired $t$-test between the coefficients for all common sites). Further abbreviations in Table 1

\begin{tabular}{|c|c|c|c|c|c|c|c|c|c|}
\hline & \multicolumn{4}{|c|}{$-1941-2000 \longleftarrow$} & \multicolumn{4}{|c|}{$-1971-2000-$} & \multirow{2}{*}{$\begin{array}{c}\text { Diff. } \\
\mathrm{p}\end{array}$} \\
\hline & Coef. & $\mathrm{SE}$ & $t$ & $\mathrm{p}$ & Coef. & SE & $t$ & $\mathrm{p}$ & \\
\hline 1 Days $<0^{\circ} \mathrm{C}$ & -0.1965 & 0.0113 & -17.40 & $<0.001$ & -0.1811 & 0.0210 & -8.62 & $<0.001$ & 0.092 \\
\hline 2 Days $>20^{\circ} \mathrm{C}$ & 0.0543 & 0.0097 & 5.60 & $<0.001$ & 0.2941 & 0.0245 & 12.02 & $<0.001$ & $<0.001$ \\
\hline 3 Spring $5^{\circ} \mathrm{C}$ threshold (DOY) & -0.1727 & 0.0164 & -10.51 & $<0.001$ & -0.2971 & 0.0306 & -9.70 & $<0.001$ & $<0.001$ \\
\hline 4 Spring $10^{\circ} \mathrm{C}$ threshold (DOY) & -0.1544 & 0.0149 & -10.33 & $<0.001$ & -0.4842 & 0.0412 & -11.76 & $<0.001$ & $<0.001$ \\
\hline 5 Autumn $10^{\circ} \mathrm{C}$ threshold (DOY) & 0.0210 & 0.0128 & 1.65 & 0.101 & 0.2108 & 0.0250 & 8.44 & $<0.001$ & $<0.001$ \\
\hline 6 Autumn $5^{\circ} \mathrm{C}$ threshold (DOY) & 0.0324 & 0.0108 & 3.00 & 0.003 & 0.2450 & 0.0250 & 9.80 & $<0.001$ & $<0.001$ \\
\hline 7 Beginning of growing season (DOY) & -0.1674 & 0.0170 & -9.82 & $<0.001$ & -0.3581 & 0.0377 & -9.49 & $<0.001$ & $<0.001$ \\
\hline 8 End of growing season (DOY) & 0.0525 & 0.0089 & 5.92 & $<0.001$ & 0.1028 & 0.0210 & 4.89 & $<0.001$ & 0.043 \\
\hline 9 Length of growing season (d) & 0.2199 & 0.0221 & 9.94 & $<0.001$ & 0.4609 & 0.0432 & 10.67 & $<0.001$ & $<0.001$ \\
\hline 10 GDD0 (degree days) & 2.356 & 0.229 & 10.27 & $<0.001$ & 10.088 & 0.3950 & 25.51 & $<0.001$ & $<0.001$ \\
\hline 11 GDD5 (degree days) & 1.387 & 0.191 & 7.28 & $<0.001$ & 8.503 & 0.3950 & 21.55 & $<0.001$ & $<0.001$ \\
\hline 12 TSUM200 (DOY) & -0.1794 & 0.0124 & -14.45 & $<0.001$ & -0.2938 & 0.0237 & -12.38 & $<0.001$ & $<0.001$ \\
\hline
\end{tabular}

Table 4. Multiple regression model of the influence of latitude, longitude and altitude on trends (regression coefficients for each station) on each of derived variables for the 1971-2000 period. Significant results are shown in bold. Abbreviations in Table 1

\begin{tabular}{|c|c|c|c|c|c|c|c|c|}
\hline & \multicolumn{2}{|c|}{ Latitude } & \multicolumn{2}{|c|}{ Longitude } & \multicolumn{2}{|c|}{ Altitude } & \multicolumn{2}{|c|}{ Overall model } \\
\hline & Coef. & $\mathrm{p}$ & Coef. & $\mathrm{p}$ & Coef. & $\mathrm{p}$ & $\mathrm{R}^{2}$ & $\mathrm{p}$ \\
\hline 1 Days $<0^{\circ} \mathrm{C}$ & -0.01737 & $<0.001$ & 0.00010 & 0.933 & -0.00030 & $<0.001$ & 29.2 & $<0.001$ \\
\hline 2 Days $>20^{\circ} \mathrm{C}$ & -0.02628 & $<0.001$ & -0.00520 & $<0.001$ & -0.00018 & $<0.001$ & 38.9 & $<0.001$ \\
\hline 3 Spring $5^{\circ} \mathrm{C}$ threshold (DOY) & -0.00383 & 0.301 & -0.00036 & 0.854 & -0.00024 & $<0.001$ & 5.7 & 0.002 \\
\hline 4 Spring $10^{\circ} \mathrm{C}$ threshold (DOY) & -0.00680 & 0.179 & 0.01121 & $<0.001$ & -0.00009 & 0.298 & 7.6 & $<0.001$ \\
\hline 5 Autumn $10^{\circ} \mathrm{C}$ threshold (DOY) & -0.00326 & 0.304 & -0.00230 & 0.158 & -0.00003 & 0.512 & 1.5 & 0.283 \\
\hline 6 Autumn $5^{\circ} \mathrm{C}$ threshold (DOY) & -0.00179 & 0.594 & -0.00525 & 0.001 & -0.00002 & 0.682 & 4.8 & 0.008 \\
\hline 7 Beginning of growing season (DOY) & -0.00125 & 0.789 & 0.00297 & 0.224 & -0.00005 & 0.528 & 0.8 & 0.580 \\
\hline 8 End of growing season (DOY) & 0.00501 & 0.052 & 0.00215 & 0.111 & 0.00005 & 0.255 & 3.0 & 0.052 \\
\hline 9 Length of growing season (d) & 0.00626 & 0.242 & -0.00082 & 0.769 & 0.00010 & 0.272 & 0.8 & 0.549 \\
\hline 10 GDD0 (degree days) & -0.33093 & $<0.001$ & -0.16585 & $<0.001$ & -0.00184 & 0.004 & 41.2 & $<0.001$ \\
\hline 11 GDD5 (degree days) & -0.42163 & $<0.001$ & -0.15727 & $<0.001$ & -0.00307 & $<0.001$ & 52.3 & $<0.001$ \\
\hline 12 TSUM200 (DOY) & -0.00650 & 0.024 & 0.00172 & 0.252 & -0.00015 & 0.002 & 5.1 & 0.004 \\
\hline
\end{tabular}

0.0210 , but was 0.2108 for the 1971-2000 period. Twothirds of stations had significantly positive trends in GDD0 and GDD5 during the 1971-2000 period (Table 2).

Table 4 summarises latitude, longitude and altitude effects on station trends (regression coefficients) in the 1971-2000 period to examine if change was uniform across Europe. Only for models of trends in numbers of cold and hot days and growing degree day accumulations did $\mathrm{R}^{2}$ exceed $10 \%$. Growing degree day (and hot day) models had negative coefficients for all 3 explanatory factors, suggesting greater accumulation trends at lower sites in the SW of Europe and smaller ones at higher sites in NE Europe. The number of cold days (and TSUM200) declined faster in higher latitude and altitude sites. However, this may be an anomaly of the data since several southern, e.g. Mediterranean, stations had few or no cold days and hence could not reduce that number.

\subsection{Maps}

Figs. A1-A12 (Appendix 1) show the contour maps for the 12 variables. Each figure contains 3 maps; (1) 1941-1970, (2) 1971-2000 and (3) the difference between the 2 periods. Most variables associated with the onset of spring show the influence of the Atlantic and thus a SW-NW gradient. To some extent the ocean influence is still apparent in autumn variables. Variables summarising summer heat (hot days, GDD0 and GDD5) have rather a S-N gradient. On most maps the influence of latitude and altitude can be discerned. Changes in spring onset variables are perhaps most obvious around the coast of France, Belgium and The Netherlands, with early areas extending inland and northwards. Because changes may be difficult to assess at a continental scale, unless there is a progression from one contour category to the next, a map of differences between the two $30 \mathrm{yr}$ periods has also 
been produced for each variable. Changes in the number of cold days, the $5^{\circ} \mathrm{C}$ spring threshold, the beginning and length of the growing season and TSUM200 seem to be greater in the centre of Europe. There is some suggestion of some areas having a later $10^{\circ} \mathrm{C}$ spring threshold. Changes in hot days, GDD0 and GDD5 appear in the positive direction except in SE Europe. Changes in autumn temperature thresholds and the end of the growing season are less easy to summarise. In broad terms the maps confirm the changes outlined in the previous sections but add spatial detail.

\section{DISCUSSION}

In the present study we have looked at a number of biologically relevant variables derived from daily mean temperature data. Temperature change is occurring across Europe, and at a faster rate in recent times. There is some suggestion that this is not happening uniformly across Europe: more obvious changes are common in central Europe (Figs. A1, A3, A4, A7, A9), western Europe (Fig. A10) or SE Europe (Figs. A2, A10, A11), and Figs. A5 \& A6 (autumn thresholds) show almost chaotic patterns. These results are in accordance with those found by Menzel et al. (2006), who showed non-uniform patterns in phenological advance across Europe, but a consistent trend towards earlier phenology.

Changes in spring onset variables were more consistent than those for summer or autumn. This is apparent in a reduction in cold days, earlier spring $5^{\circ} \mathrm{C}$ threshold, earlier beginning of the growing season and earlier TSUM200. Changes in autumn are less clear, but on balance would indicate a delay. This is in agreement with the mixed results for autumn phenological change reported by Menzel et al. (2006). The nature of these changes may induce greater changes, phenological and otherwise, in species associated with early spring and low temperatures rather than those of summer.

We have only used temperature data up to the year 2000. Given that temperatures in the first few years of the 21st century have been very warm (e.g. mean global annual temperature: $1941-1970=14.0^{\circ} \mathrm{C}$, $1971-2000=14.2^{\circ} \mathrm{C}, 2001-2007=14.7^{\circ} \mathrm{C}$; based on station data from www.data.giss.nasa.gov), the changes reported here are likely to continue to intensify.

We think that these are the first European maps of temperature isochrones and other biologically relevant temperature summaries for over a century. With the increasing availability of temperature data and the increasing capabilities of GIS software we hope that improvements to and updates of these maps will continue. For example, since we started this project a gridded daily minimum, maximum and mean temperature datasset for Europe (Haylock et al. 2008) has become available. This will provide more opportunities to examine influences of temperature on species development across Europe.

Acknowledgements. We owe a huge debt of gratitude to A. M. G. Klein Tank and co-workers for making this resource freely available for research. This paper was partly funded by a grant of the Estonian Science Foundation No. ETF7204. We thank 2 anonymous reviewers for their input.

\section{LITERATURE CITED}

Bartholomew JG, Herbertson AJ, Buchan A (1899) Bartholomew's physical atlas, Vol 3. Meteorology. Archibald Constable \& Co, London

Haylock MR, Hofstra N, Klein Tank AMG, Klok EJ, Jones PD, New M (2008) A European daily high-resolution gridded data set of surface temperature and precipitation for 1950-2006. J Geophys Res 113:D20119, doi:10.1029/2008 JD010201

Klein Tank AMG, Wijngaard JB, Können GP, Böhm R and 35 others (2002) Daily dataset of 20th-century surface air temperature and precipitation series for the European Climate Assessment. Int J Climatol 22:1441-1453

Menzel A, Sparks TH, Estrella N, Koch E and 27 others (2006) European phenological response to climate change matches the warming pattern. Glob Change Biol 12: 1969-1976

Mitchell T, Hulme M (2002) Length of the growing season. Weather 57:196-198

Southern HN (1938) The spring migration of the swallow over Europe. Br Birds 32:4-7 
Appendix 1. Changes in 12 biologically relevant temperature variables across Europe, 1941-2000
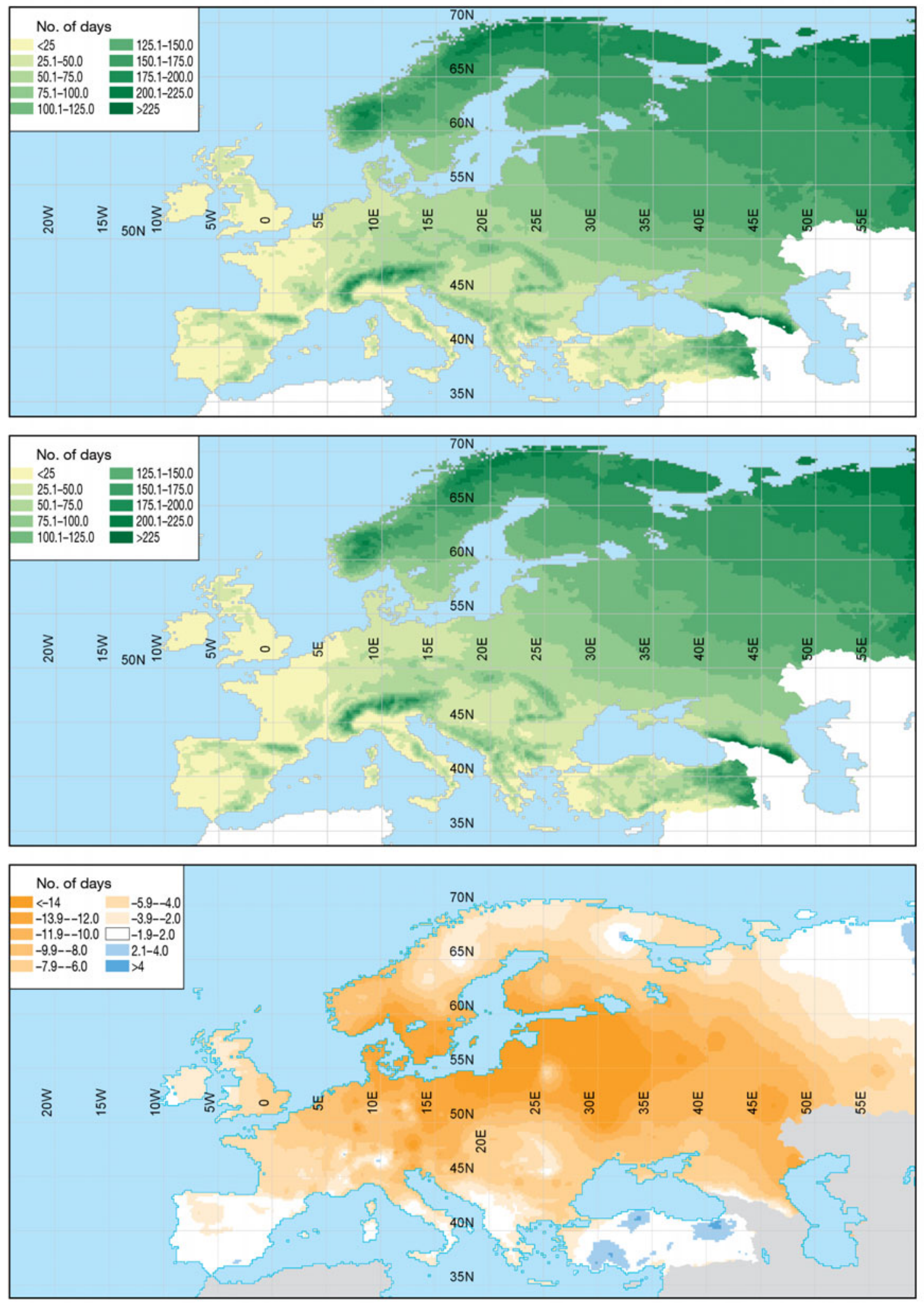

Fig. A1. Number of cold days (daily mean air temperature $<0^{\circ} \mathrm{C}$ ) in Europe for 1941-1970 (upper), $1971-2000$ (middle) and difference between periods (lower) 

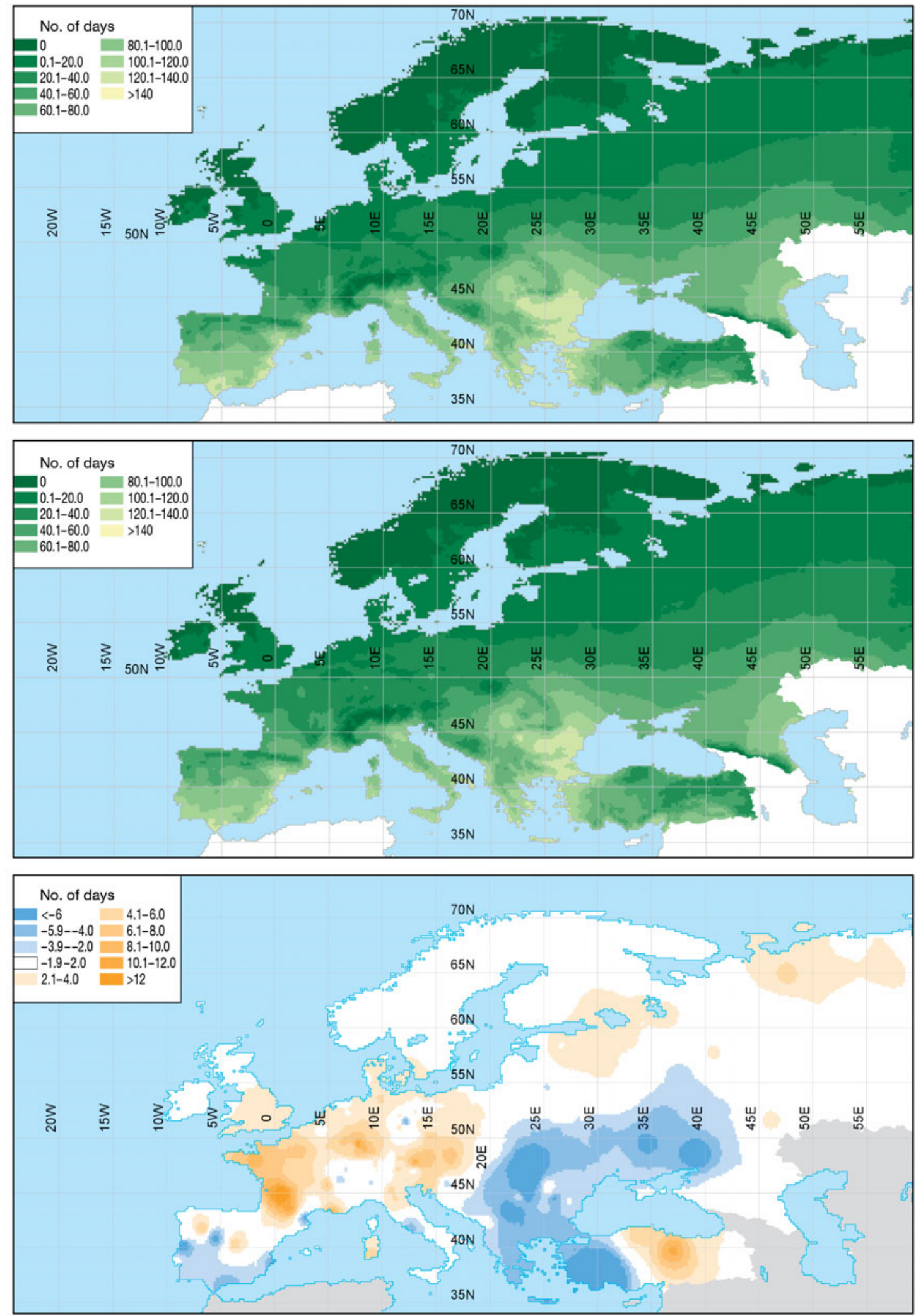

Fig. A2. Number of warm days (daily mean air temperature $>20^{\circ} \mathrm{C}$ ) in Europe for 1941-1970 (upper), $1971-2000$ (middle) and difference between periods (lower) 

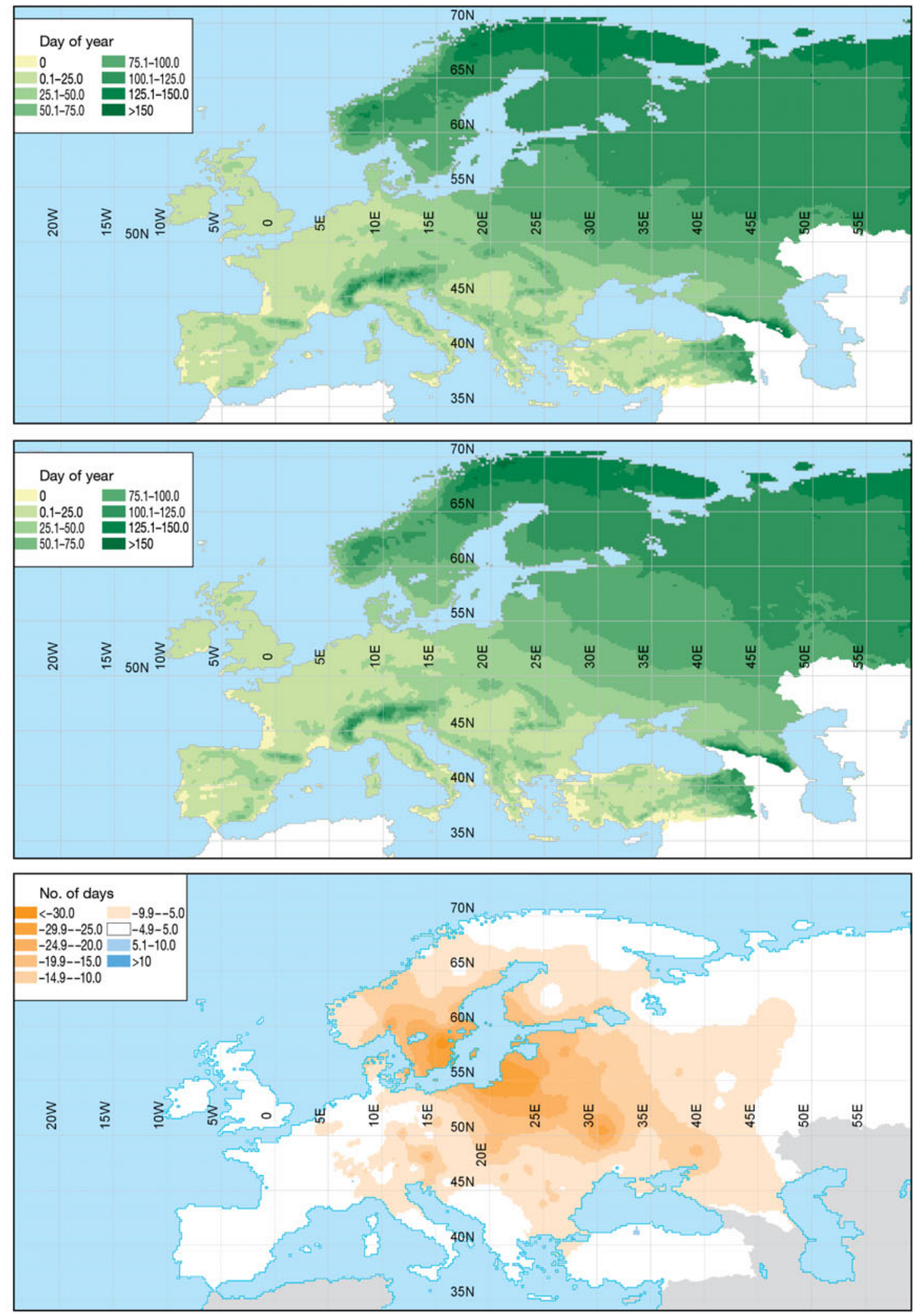

Fig. A3. Day of the year on which spring temperatures first rose above a $5^{\circ} \mathrm{C}$ threshold in Europe for 1941-1970 (upper), 1971-2000 (middle) and difference between periods (lower) 

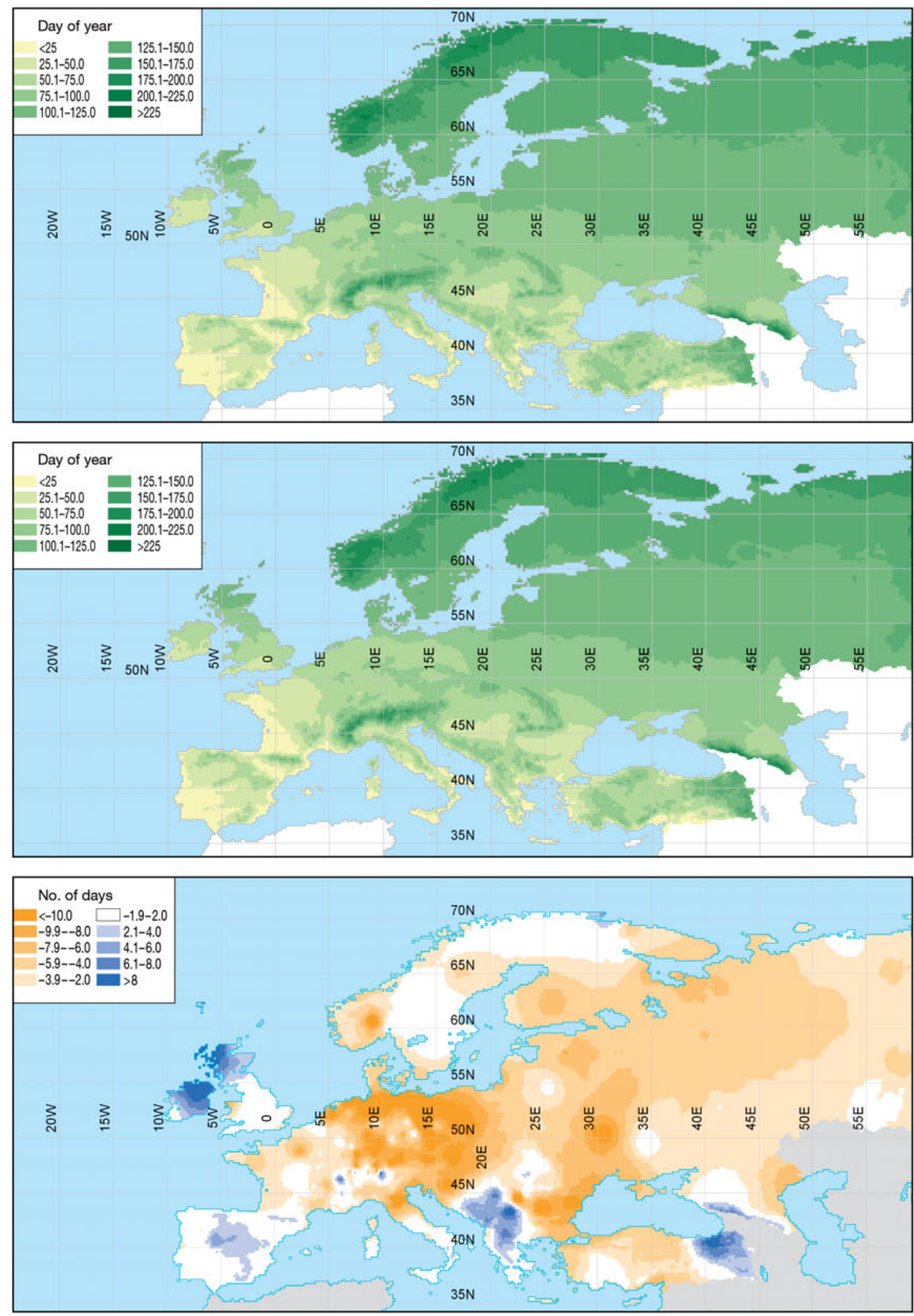

Fig. A4. Day of the year on which spring temperatures first rose above a $10^{\circ} \mathrm{C}$ threshold in Europe for 1941-1970 (upper), 1971-2000 (middle) and difference between periods (lower) 

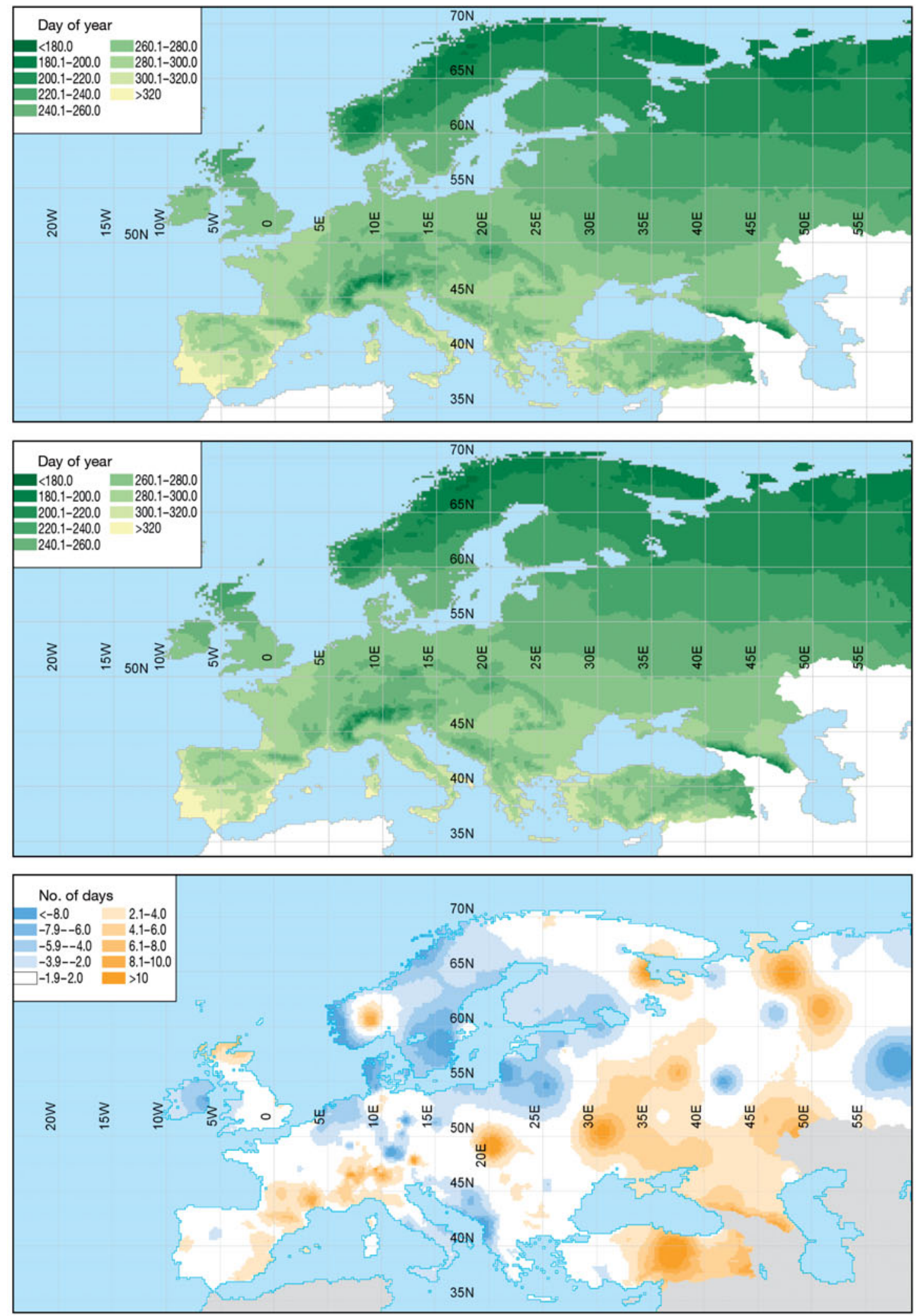

Fig. A5. Day of the year on which autumn temperatures first fell below a $10^{\circ} \mathrm{C}$ threshold in Europe for $1941-1970$ (upper), 1971-2000 (middle) and difference between periods (lower) 

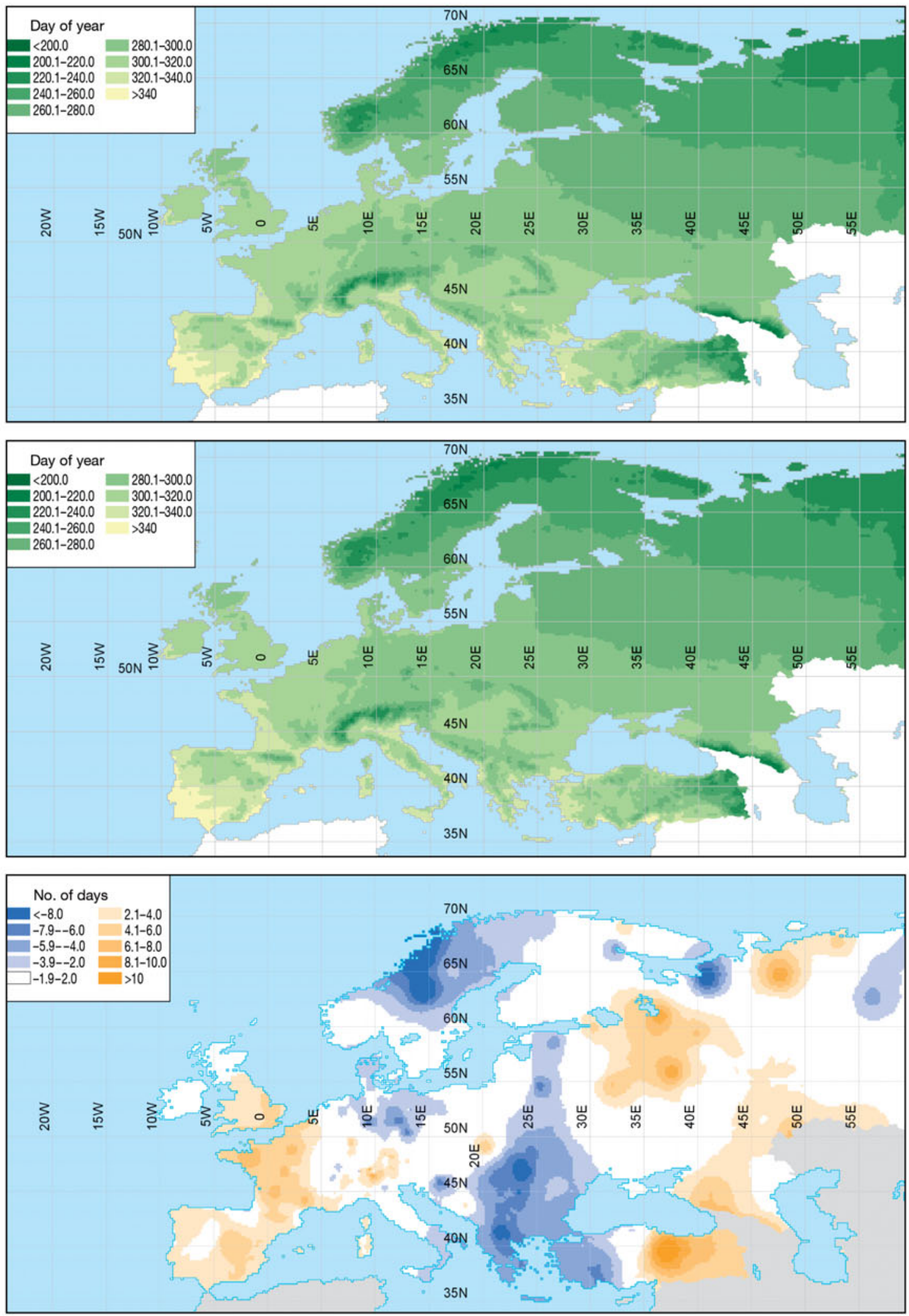

Fig. A6. Day of the year on which autumn temperatures first fell below a $5^{\circ} \mathrm{C}$ threshold in Europe for 1941-1970 (upper), 1971-2000 (middle) and difference between periods (lower) 

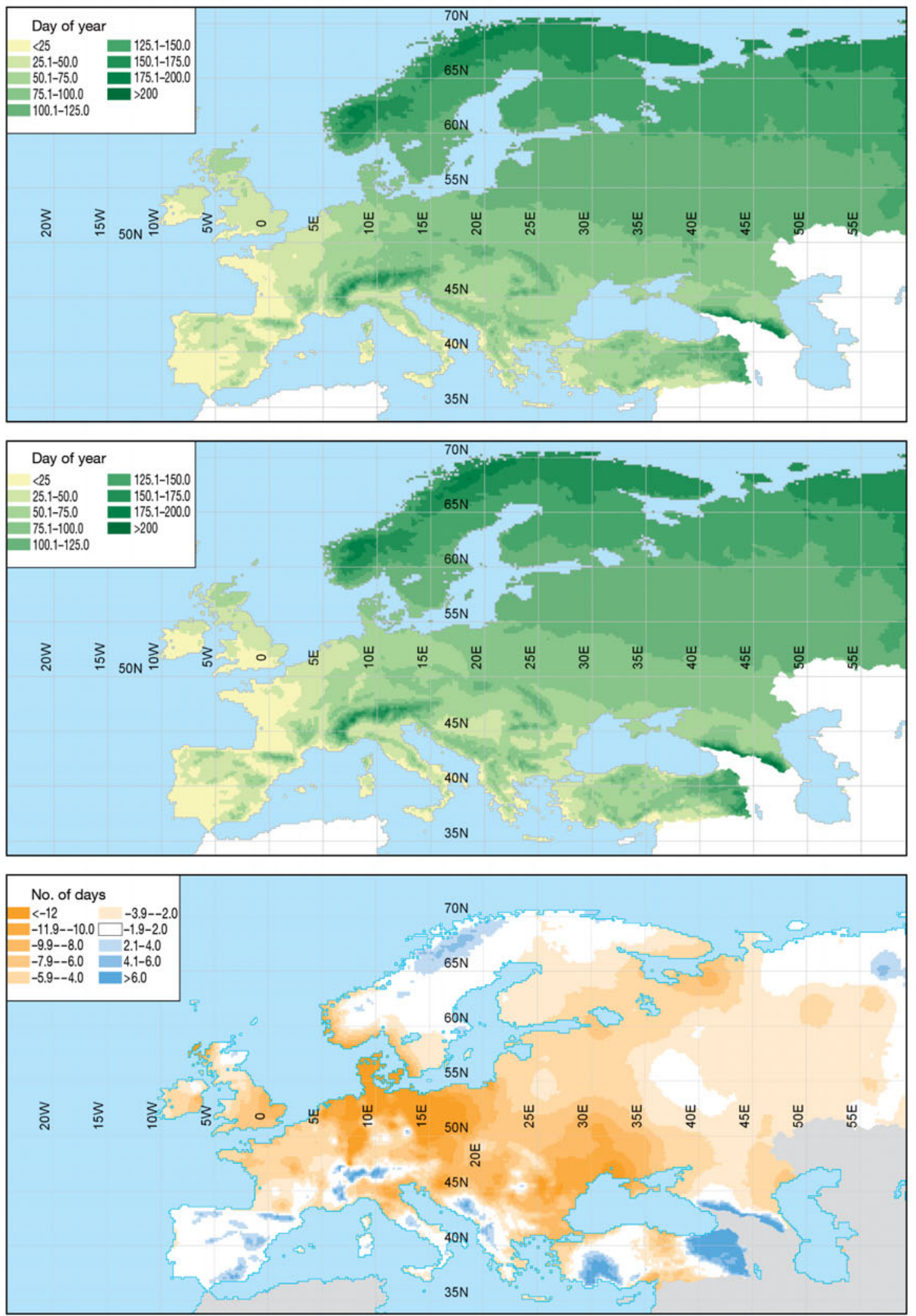

Fig. A7. Day of the year marking the beginning of the growing season (see '2.1. Data' for details) in Europe for 1941-1970 (upper), 1971-2000 (middle) and difference between periods (lower) 

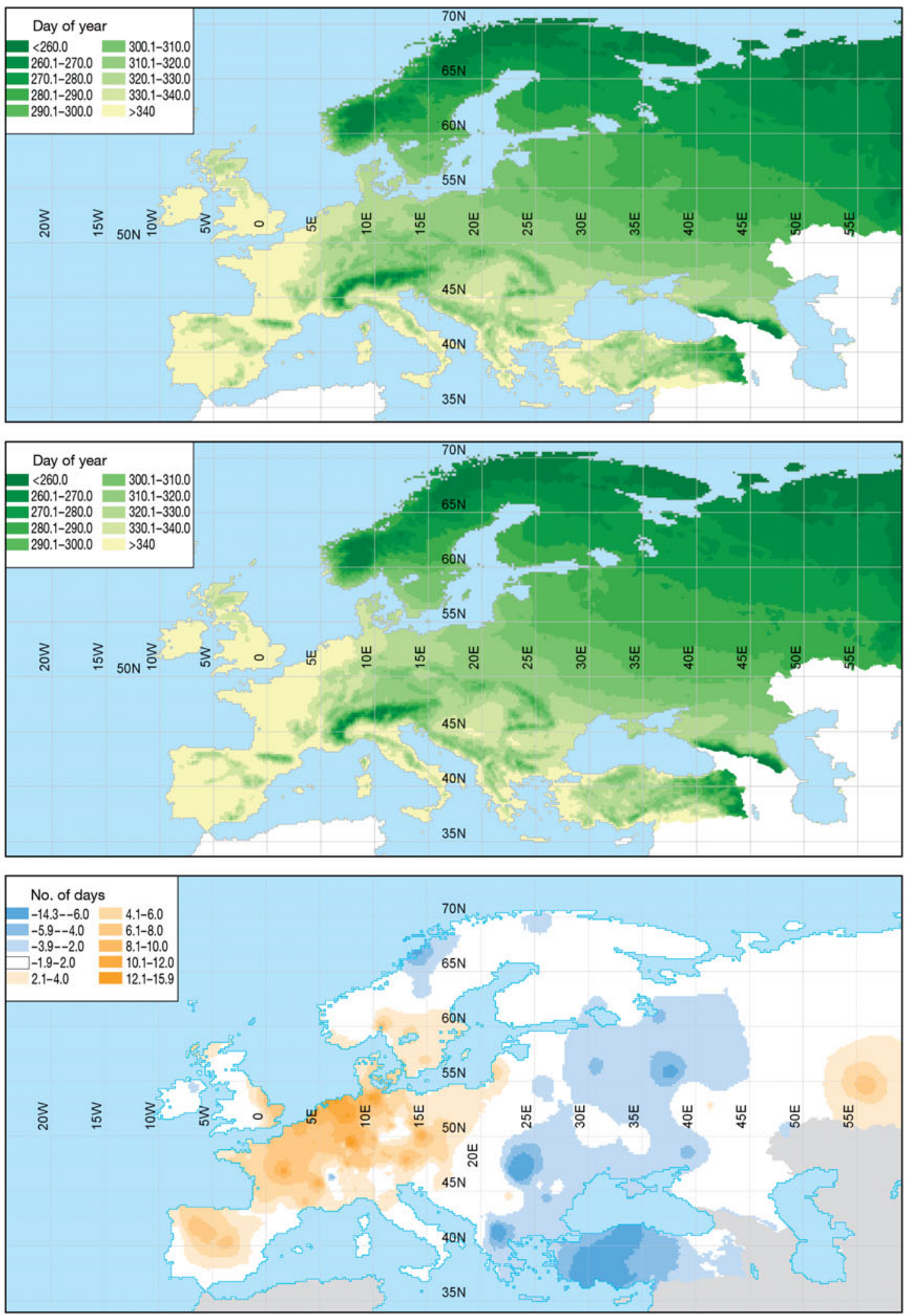

Fig. A8. Day of the year marking the end of the growing season (see '2.1. Data' for details) in Europe for 1941-1970 (upper), 1971-2000 (middle) and difference between periods (lower) 

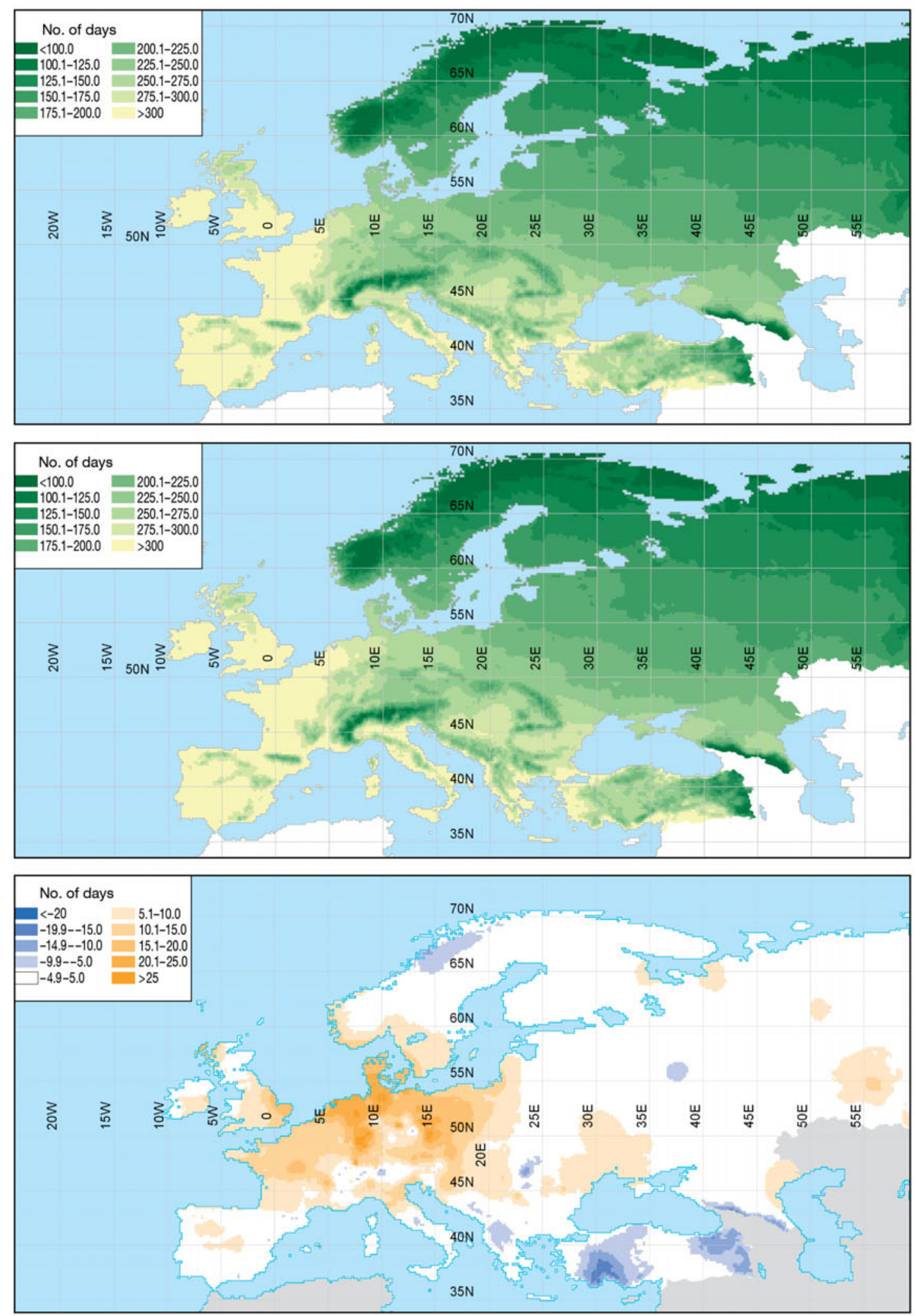

Fig. A9. Length of the growing season (see '2.1. Data' for details) in Europe for 1941-1970 (upper), 1971-2000 (middle) and difference between periods (lower) 

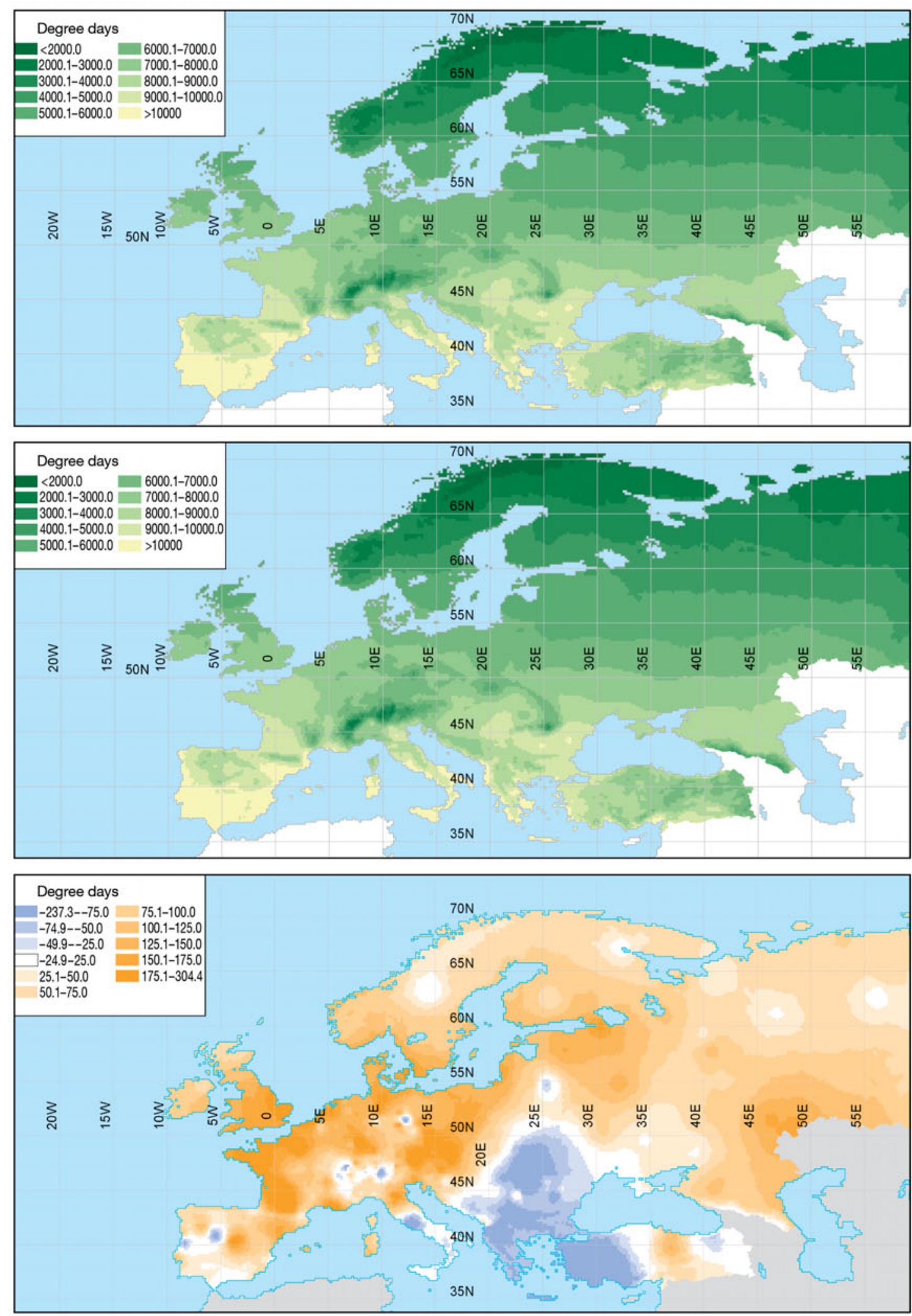

Fig. A10. Annual accumulated degree days above $0^{\circ} \mathrm{C}$ (GDD0) in Europe for 1941-1970 (upper), $1971-2000$ (middle) and difference between periods (lower) 

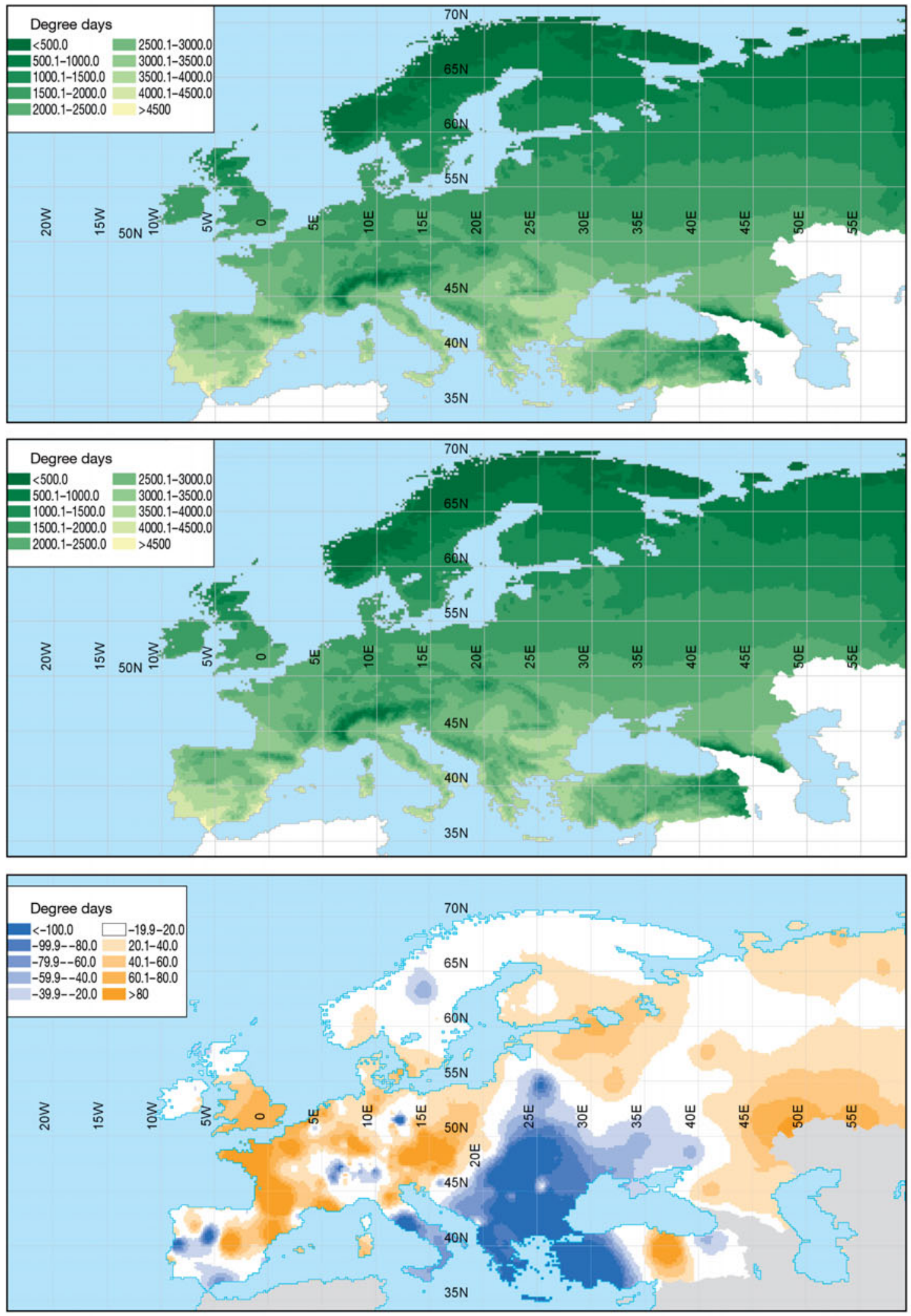

Fig. A11. Annual accumulated degree days above $5^{\circ} \mathrm{C}$ (GDD5) in Europe for 1941-1970 (upper), $1971-2000$ (middle) and difference between periods (lower) 

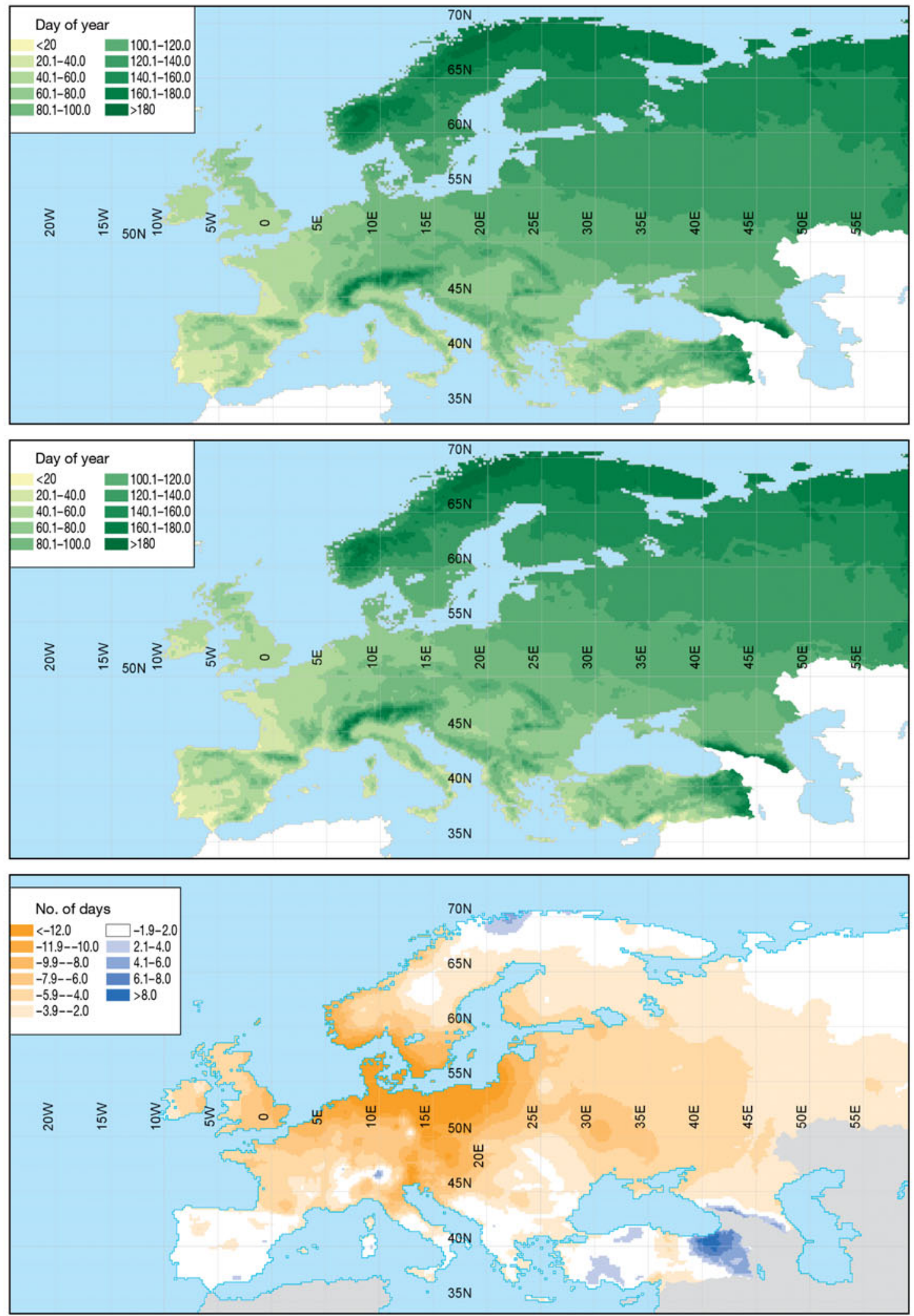

Fig. A12. Day of the year when accumulated temperature above $0^{\circ} \mathrm{C}$ reached 200 degree days (TSUM200) in Europe for 1941-1970 (upper), 1971-2000 (middle) and difference between periods (lower) 